\title{
Prevalence and awareness of oral manifestations among people living with HIV/AIDS attending counselling and treatment centres in Iringa Municipality, Tanzania
}

\author{
IBRAHIM E.A.T. MWANGOSI ${ }^{1 *}$ and JULITHA M. MAJENGE² \\ ${ }^{1}$ Muhimbili School of Assistant Dental Officers, Institute of Allied Health Sciences, P.O. Box 66521, Dar es \\ Salaam, Tanzania \\ 2Iringa Municipal Council, Iringa, Tanzania
}

\begin{abstract}
There is limited literature on the magnitude of oral manifestations and the extent of awareness on its occurrence in people living with HIV/AIDS (PLWHA) in Tanzania. The objective of this study was to assess the magnitude of, and extent of awareness on oral manifestations among PLWHA attending counselling and treatment centres (CTC) in Iringa Municipality in south-western Tanzania. A convenient sample of 200 PLWHA was included in the study in two CTC. Each participant was interviewed using a structured questionnaire. Thereafter a quick clinical oral assessment by a dentist was performed to record any relevant abnormality. The mean age of participants was $38.4 \pm 11.9$ years. Females were $63.3 \%$ and most of the participants had primary education (53\%). Generally, $23.5 \%$ of the PLWHAs had at least one oral manifestation, with statistical significant difference across age groups. Clinical manifestations observed were mucosal ulcerations with or without severe periodontal lesions $(7.0 \%)$, angular chelitis $(7.0 \%)$, oral thrush (6.5\%), Kaposi's sarcoma (1.5\%), and hairy leukoplakia (1.0\%). The majority (89.5\%) of the PLWHAs had sound awareness on clinical oral manifestations with significant statistical difference by educational status - the strength increased linearly with educational status. In general, $77.0 \%$ of the PLWHAs had healthy oral cavities. In conclusion, the prevalence and severity of clinical oral manifestations among PLWHA was low and the majority of PLWHA were aware of the conditions. However, it is recommended that more intensive studies should be carried out to assess the standard strength of the public awareness on oral manifestations among PLWHA and ascertain the magnitude of the problem and facilitate appropriate control strategies.
\end{abstract}

Keywords: awareness, oral manifestations, HIV/AIDS, Tanzania

\section{Introduction}

There is limited literature showing the magnitude of oral manifestations and the extent of awareness on its occurrence in people living with HIV/AIDS (PLWHA) in Tanzania. Oral manifestations are reported to have clinical significance in HIV/AIDS across the globe. A number of oral conditions associated with HIV/AIDS have been reported globally. These include Kaposi's sarcoma, oral fungal infections, repeated oral ulcers to mention just a few (Sharma et al., 2006; Tirwonwe et al., 2007; Gennaro et al., 2008; Adedigba et al., 2008; Zhang et al., 2009). Very often, oral manifestations such as candidiasis, oral hairy leukoplakia, herpetic ulcers and Kaposi's sarcoma appear frequently as the early symptoms of HIV infection (Naidoo \& Chikte, 1999; Peterson, 2006; Olaniyi \& Sunday, 2005; Gennaro et al., 2008). In East Africa, similar conditions have been reported in Kenya and Uganda, although with different relative proportions - due to a number of reasons, such as different diagnostic criteria and levels of

\footnotetext{
* Correspondence: Dr. Ibrahim Mwangosi; Email: ieatmwangosi@yahoo.com
} 
awareness and identification skills among professionals and the public (Butt et al., 2001; Tiromwe et al., 2007).

The fact that many oral manifestations occurs early in people living with HIV/AIDS, and that some specific oral manifestations strongly appears to be associated with levels of immune suppression and moderately associated with highly viral burden (Patton, 2000), oral manifestations could be used as markers that suggest progression of the disease. As such, oral manifestations have sometimes been suggested to offer suspicion of acute sero-conversion illness, thereby allowing an alternative means of staging the disease progression in addition to paving an entry point or end point criteria for clinical trials for antiretroviral drugs (Patton \& Van der Horst, 1999).

Relationship of oral manifestations to HIV/AIDS justifies the essence for the dental health workers to be familiarised with contemporary skills in early diagnosis of such lesions to aid proper and early management of the disease (Patton \& Van der Horst, 1999; Lyles, 2001). With the introduction and use of antiretroviral drugs, along with increasing knowledge on HIV and its commonly associated opportunistic infections, the trend of oral manifestations has been greatly modified (Greenwood et al., 2002; Kaste \& Bednarsh, 2007; Kisangau et al., 2007). This is regardless the type of medication involved, whether by traditional healing or modern-western (Rudolph et al., 2007).

Tanzanian studies on oral manifestation with relation to HIV/AIDS offers important time-based divergent information. Hiza et al. (1991) reported that $64 \%$ of sero-positive patients had oral manifestations when compared to $4 \%$ of HIV sero-negative patients in Muhimbili National Hospital in which, oral candidiasis was the most common lesion. Kahabuka et al. (2007) reported that $87 \%$ people living with HIV in Dar es Salaam had oral ulcers and $84 \%$ had oral candidiasis. In the same study, a large proportion of the PLWHAs reflected a gross capability in associating HIV/AIDS to oral manifestations which they were suffering from. However, such reports are not nationwide; more studies are essential to add information to what is available, thereby drawing a wider understanding of the situation in Tanzania. It was the objective of this study therefore, to assess the magnitude of, and extent of awareness on oral manifestations among PLWHAs attending counselling and treatment centres in Iringa Municipality, Tanzania.

\section{Materials and Methods}

\section{Study area and design}

This cross sectional study was conducted in Iringa Municipality in south-western Tanzania. The location of the study area has been previously described by Mboera et al. (2006). The study involved 200 prior diagnosed individuals with serum positive for HIV in May 2008, at two conveniently chosen counselling and treatment centres. Every individual attending a selected CTC was eligible for participation into the study. It was learnt that clients in those CTCs were reappointed every month for review and re-collection of drugs. Every third attending individual was selected to participate into the study; if not willing to join the next person was opted based on their arrival sequence. 


\section{Data collection}

An interview using a structured questionnaire was done in a separate room with bright electric light and optimum ventilation. Socio-demographic characteristics of each participant (age, educational status, gender) were recorded. Participants were asked to mention any frequent oral manifestation which they considered to affect people living with HIV/AIDS. This interview was followed by a short clinical assessment of oral health status whereby, all soft and hard tissue lesions were recorded whenever noted. When no visible lesion was found it was recorded as "healthy oral cavity" Inter-examiner calibrations was done to $20 \%$ of the participants and the reliability coefficient (Alpha) was good $(\alpha=0.86)$.

Various forms of the reported oral manifestations that were suggested by participants to be linked to HIV/AIDS were re-categorised into two groups. The named oral manifestations which were scientifically accepted to relate with HIV/AIDS were coded as correct; otherwise, any named oral manifestation whose relationship with HIV/AIDS could not be scientifically proved was coded "incorrect". The following simplified operational definitions were used as diagnostic criteria: Hairy leukoplakia - clinically can be seen as a flat, white plaque; either small or long white projections with pointed or blunted ends (www.maxillofacialcenter.com/). Kaposi sarcoma (KS) clinically presents as nodules or blotches that may be red, purple, brown, or black, and are usually papular - palpable or raised (http://en.wikipedia.org/). Periodontal disease named for gums which are bleeding, swollen, recessed and bad breath (http://www.umm.edu/). A participant could have one or more conditions and for descriptive purpose a term "with" was used for grouping multiple conditions.

\section{Data analysis}

Data was analysed using SPSS version 13. Cross-tabulations and frequency distributions were deliberated across two groups (15-39 years and 40+ years) to obtain almost equally sized groups for comparison purposes. Moreover, data was analysed through five age groups (15-19 years, 20-29 years, 30-39 years, 40-49 years, 50+ years) and then by two merged age groups (15-39 years, 40+ years) in order to examine a phenomenon within broader groups to allow future more focused age-group specific tailor-made intervention programmes. Data analysis was also performed against educational levels, and sex. Chi-square statistic was computerised against $\mathrm{p} \leq 0.05$ critical value for comparisons

\section{Ethical considerations}

This study received ethical approval from the Institute of Allied Health Sciences, of the Muhimbili University of Health and Allied Health Sciences. Local permission to conduct the study was obtained from the Executive Director of Iringa Municipal Council, Medical Officer In-charge and Heads of Counselling Treatment Centres. Individual informed consent was sought before enrolment of the participants.

\section{Results}

Overall response rate was $100 \%$. The minimum questions-specific response rate was $98 \%$. According to Table 1, females were $63.5 \%(n=127)$ and males were $36.5 \%(n=73)$. The mean age group was $38.4 \pm 11.9$. The larger proportion of the PLWHA in this study had a primary education $(53 \%, \mathrm{n}=106)$ (Table 1$)$. 
Table 1: Demographic characteristics of the respondents $(\mathrm{N}=\mathbf{2 0 0})$

\begin{tabular}{llll}
\hline Variable & Response & \multicolumn{2}{l}{ Frequency } \\
& & $\%$ & $\mathrm{~N}$ \\
\hline Age group (years) & $15-19$ & 4.5 & 9 \\
& $20-29$ & 19 & 38 \\
& $30-39$ & 33.5 & 67 \\
& $40-49$ & 24.5 & 49 \\
Sex & $\geq 50$ & 18.5 & 37 \\
Education & Females & 63.5 & 127 \\
& Males & 36.5 & 73 \\
& None & 24.5 & 49 \\
& Primary & 53 & 106 \\
& Secondary/College & 22.5 & 45 \\
\hline
\end{tabular}

Table 2: Frequency distribution of PLWHAs on the correct awareness of diverse forms of oral manifestations by educational status

\begin{tabular}{lll}
\hline Educational status & Number of respondents & Percent \\
\hline None & 36 & 73.5 \\
Primary & 98 & 92.5 \\
Secondary and college & $45^{*}$ & 100 \\
\hline Total & $\mathbf{1 7 9}$ & $\mathbf{8 9 . 5}$ \\
\hline
\end{tabular}

$*\left(\mathrm{P}=0.000, \chi^{2}=19.662\right)$.

A total of 179 (89.5\%) of the PLWHAs had sound awareness on the diverse oral manifestations. However, the knowledge differed linearly across educational status from $100 \%$ of those with secondary or college education to $73.5 \%$ of those with informal education, with significant statistical difference $\left(P=0.000, \chi^{2}=19.662\right)$. There was no statistical significant difference across sex and age groups on the levels of awareness. The most frequently mentioned as perceived oral manifestations were oral ulcerations, severe periodontal disease unyielding to treatment, angular chelitis, oral tumours, oral thrush, and prolonged oral tonsillitis - either each one alone or in a combination.

Generally, the observed clinical oral manifestations among PLWHAs were in the following descending order: mucosal ulcerations with or without severe periodontal lesions $(7.0 \%)$, angular chelitis $(7.0 \%)$, oral thrush $(6.5 \%)$, Kaposi's sarcoma $(1.5 \%)$, and hairy leukoplakia $(1.0 \%)$. There was statistical significant difference across age groups $(P=0.004$, $\left.\chi^{2}=20.792\right)$. About a quarter $(23.5 \%)$ of the PLWHAS had at least one oral manifestation. The difference was statistically significant across age groups $\left(P=0.004, \chi^{2}=17.372\right)$. There were no significant differences observed across educational status or sex (Table 3 ).

Table 3: Frequency distribution of oral manifestations observed in PLWHA across age groups

\begin{tabular}{|c|c|c|c|c|c|c|}
\hline \multirow[t]{2}{*}{ Oral manifestation } & \multicolumn{2}{|c|}{ 15-39 years } & \multicolumn{2}{|c|}{$40+$ years } & \multicolumn{2}{|c|}{ Total } \\
\hline & $\mathbf{N}$ & $\%$ & $\mathbf{N}$ & $\%$ & $\mathbf{N}$ & $\%$ \\
\hline Healthy oral cavity & 99 & 86.6 & 55 & 64.0 & 154 & 77.0 \\
\hline Mucosal ulcerations/ advanced periodontal disease & 2 & 1.8 & 2 & 14.0 & 14 & 7.0 \\
\hline Kaposi's sarcoma & 1 & 0.9 & 2 & 2.3 & 3 & 1.5 \\
\hline Oral thrush & 6 & 4.4 & 7 & 8.1 & 13 & 6.5 \\
\hline Angular chelitis & 5 & 3.5 & 9 & 10.5 & 14 & 7 \\
\hline Hairy leukoplakia & 1 & 0.9 & 1 & 1.2 & 2 & 1.0 \\
\hline
\end{tabular}




\section{Discussion}

Generally, a quarter of the participating PLWHAs had at least one oral manifestation, with statistical significant difference across age groups. The prevalence in this study was higher than that reported by Bendick et al. (2002) who found only $10 \%$ of patients with oral manifestations in Cambodian study. According to Bendick et al. (2002), his findings were linked to an intense poverty that limited people's access to medical facilities. This is not the case in current study in which the participants enjoyed a fair access to the CTCs. However, it should be noted that the current study was a cross-section and included PLWHAs who voluntarily sought medical attention. Inclusion of those remaining at home in the whole municipality would probably change the whole picture of the findings.

The observed clinical oral manifestations in this study were mucosal ulcerations with or without severe periodontal lesions, angular cheilitis, oral thrush, Kaposi's sarcoma and hairy leukoplakia. These oral manifestations are consistent with several other reports across the globe (Rudolf \& Ogunbodede, 1999; Sharma et al., 2006; Flint et al., 2006; Petersen 2006; Tiromwe et al., 2007; Kahabuka et al., 2007; Genaro et al., 2008). Unpublished reports also indicate that Herpes simplex, oral candidiasis, hairy leukoplakia and Kaposi's sarcoma are common oral manifestations among PLWHA in Dar es Salaam (Monthly Dar es Salaam Coordinators' Overview Reports). The low proportions of oral manifestations in this study are likely to have been influenced by use of anti-retroviral treatment which has been made widely since 2004 . Petersen (2006) and Greenwood et al., 2002 also emphasized that in most developed countries alike, the availability and consistent use of antiretroviral drugs had dramatic reduction effect on the HIV-related morbidity and mortality. Opportunistic conditions are greatly modified in the era of antiretroviral drugs and increased knowledge of combating the insurgence (Kaste et al., 2007). At times, the antiretroviral drugs trigger the environment towards emergence of oral manifestations in the form of either side effects or as toxic complications (Flint et al., 2006). All of the participants in the current study were at different stages of antiretroviral therapies, being seen when they were on their routine appointment for evaluation and collection of more drugs. Antiretroviral drugs are clearly connected to the modified status of oral manifestations in a number of studies (Kaste et al., 2007; Tironwe et al., 2007).

Oral leukoplakia was predominant among 40+ years old individual, contrary to findings by Sharma et al. (2006) who observed a higher prevalence among young individual (<35 years). The differences in diagnostic techniques and skills, cultural influential differences, sample sizes and different study designs could probably explain this difference. In the current study, the majority of the participants were aware of various forms of oral manifestations. The level of education significantly predicted the level of sound awareness on oral manifestations in relation to HIV/AIDS, probably explained by inclusion of HIV/AIDS topics in the school curriculum. On the contrary, sex and age offered no statistical significant difference in their awareness status could reflect an equal opportunity towards information access and limitations in the society regardless age and sex. Already, Rudolf et al. (2007) observed that individuals of all levels of educational status are likely to access information on oral manifestation. However, in our study individuals with secondary or college were more knowledgeable than those without formal education. It is often hypothesized that many people fairly know the pathophysiology of HIV/AIDS these days. Nevertheless, many individuals continue to show deficiency in consistently applying standard skills to identify early features of oral manifestations and to 
promptly manage them rationally - professionals and laymen alike (Lyles, 2001; Erasmus et al., 2005; Kisangau et al., 2006).

In conclusion, oral manifestations among PHWHA in Iringa Municipality are prevalent, though with significant variation across age groups; and that a larger proportion of the affected individuals are aware of the oral conditions associated with HIV/AIDS. Nonetheless, studies that are more intensive are necessary to assess the standard strength of the awareness of the public on oral manifestations in PLWHAs and ascertain the magnitude of the problem to facilitate intensified strategies towards control. Oral health professionals should focus on educating the society and particularly PLWHAs on the common oral manifestations in association with HIV/AIDS. In addition to this, oral health professionals should constantly prioritize regular checkups of PLWHAs as one of the basic supportive measures.

\section{References}

Adedigba, M.A., Ogunbodede, E.O., Jeboda, S.O., Naidoo, S. (2008) Patterns of oral manifestation of HIV/AIDS among 225 Nigerian patients. Oral Disease 14, 341-346.

Bendick, C., Scheifele, C. \& Reichart, P.A. (2002) Oral manifestations in 101 Cambodians with HIV and AIDS. Journal of Oral Pathology Medicine 31, 1-4.

Butt, F.M., Chindia, M.L., Vaghela, V.P. \& Mandalia, K. (2001) Oral manifestations of HIV/AIDS in a Kenyan provincial hospital. East African Medical Journal 78,398-401.

Erasmus, S., Luiters, S. \& Brijlal, P. (2005) Oral hygiene and dental student's knowledge, attitude and behaviour in managing HIV/AIDS patients. International Journal of Dental Hygiene 3:213-217.

Flint, S.R., Tappuni, A., Leigh, J., Schmidt-Westhausen, A.M. \& MacPhail, L. (2006) Markers of immunodeficiency and mechanisms of HAART therapy on oral lesions. Advanced Dental Research 19,146-151.

Gennaro, S., Naidoo, S. \& Berhold, P. (2008) Oral health and HIV/AIDS. MCN American Journal of Maternity and Childhood Nursing 33, 50-57.

Greenwood, I., Zakrzewska, J.M. \& Robinson, P.G. (2002) Changes in the prevalence of HIVassociated mucosal disease at a dedicated clinic over 7 years. Oral Disease 8, 90-94.

Hiza, J.F.R., Bakilana, I., Bygberg, M., Scheutz, J.R., Shoe, L.B. \& Feber, R. (1991) Oral manifestations of HIV infection. Tanzania Medical Journal 6, 77.

Kahabuka, F., Fabian, F., Petersen, P.E. \& Nguvumali, H. (2007) Awareness of HIV/AIDS and its oral manifestations among people living with HIV in Dar es Salaam, Tanzania. African Journal of AIDS Research 1:91-95.

Katse, L.M. \& Bednarsh, H. (2007) The third decade of HIV/AIDS: a brief epidemiologic update for dentistry. Journal of Canadian Dental Association 73,941-944.

Kisangau, D.P., Lyaruu, H.V., Hosea, K.M. \& Joseph, C.C. (2007) Use of traditional medicines in the management of HIV/AIDS opportunistic infections in Tanzania: a case in Bukoba rural district. Journal of Ethnobiology and Ethnomedicine 10, 3-29.

Lyles, A.M. (2001) What the dentist should know about a patient with HIV/AIDS. Journal of California Dental Association 29,158-169.

Maxillofacial

Center. Http://www.maxillofacialcenter.com/BondBook/mucosa/hairyleuk.html\#Clinical) 
Mboera, L.E.G., Kadete, L., Nyange, A. \& Molteni, F. (2006) Urban malaria in Dodoma and Iringa, Tanzania. Tanzania Health Research Bulletin 8, 115-118 .

Naidoo S. \& Chikte U. (1999) HIV/AIDS-the evolving pandemic and its impact on oral health in sub-Saharan Africa. South Africa Dental Journal 54, 616-630.

Olaniyi, T.O. \& Sunday, P. (2005 Oral manifestations of HIV infection in 36 Nigerian children. Journal of Clinical Pediatric Dentistry 30, 89-92.

Patton, L.L. (2000) Sensitivity, specificity and positive predictive value of oral opportunistic infections in adults with HIV/AIDS as markers of immune suppression and viral burden. Oral Surgery Oral Medicine Oral Pathology Oral Radiology and Endodontics 90,182188.

Patton, L.L. \& Van der Horst, C. (1999) Oral infections and other manifestations of HIV disease. Infectious Disease Clinical North America 13, 879-900.

Peterson, P.E. (2006) Policy for prevention of oral manifestations in HIV/AIDS; the approach of the WHO Global Oral Health Program. Advanced Dental Research 19, 17-20.

Rudolph, M.J., Ogunbodede, E.O., Mistry, M. (2007) Management of the oral manifestations of HIV/AIDS by traditional healers and care givers. Curationis 30, 56-61.

Sharma, G., Pai, K.M., Suhas, S., Ramapuram, J.T., Doshi, D. \& Anup, N. (2006) Oral manifestations in HIV/AIDS infected patients in India. Oral Disease 12, 537-542

Tirwonwe, J.F., Rwenyonyi, C.M., Muwazi, L.M., Besigye, B. \& Mboli, F. (2007) Oral manifestations of HIV/AIDS in clients attending TASO clinics in Uganda. Clinical Oral Investigation 11, 289-292

Wikipedia. (http://en.wikipedia.org/wiki/Kaposi's_sarcoma\#Mouth)

Zhang, X., Reichart, P.A. \& Song, Y. (2009) Oral manifestations of HIV/AIDS in China. Oromaxillofacial Surgery (Epub ahead of print) 